\title{
Genome-wide investigation and functional characterization of the $\beta$-ketoadipate pathway in the nitrogen-fixing and root-associated bacterium Pseudomonas stutzeri A1501
}

Danhua $\mathrm{Li}^{1,2+}$, Yongliang Yan ${ }^{2 \dagger}$, Shuzhen Ping ${ }^{2}$, Ming Chen ${ }^{2}$, Wei Zhang ${ }^{2,3}$, Liang Li ${ }^{2}$, Wenna Lin², Lizhao Geng ${ }^{2}$, Wei Liu', Wei Lü, ${ }^{2,3^{*}}$, Min Lin ${ }^{1,2^{*}}$

\begin{abstract}
Background: Soil microorganisms are mainly responsible for the complete mineralization of aromatic compounds that usually originate from plant products or environmental pollutants. In many cases, structurally diverse aromatic compounds can be converted to a small number of structurally simpler intermediates, which are metabolized to tricarboxylic acid intermediates via the $\beta$-ketoadipate pathway. This strategy provides great metabolic flexibility and contributes to increased adaptation of bacteria to their environment. However, little is known about the evolution and regulation of the $\beta$-ketoadipate pathway in root-associated diazotrophs.

Results: In this report, we performed a genome-wide analysis of the benzoate and 4-hydroxybenzoate catabolic pathways of Pseudomonas stutzeri A1501, with a focus on the functional characterization of the $\beta$-ketoadipate pathway. The $P$. stutzeri A1501 genome contains sets of catabolic genes involved in the peripheral pathways for catabolism of benzoate (ben) and 4-hydroxybenzoate (pob), and in the catechol (cat) and protocatechuate (pca) branches of the $\beta$-ketoadipate pathway. A particular feature of the catabolic gene organization in A1501 is the absence of the catR and pcaK genes encoding a LysR family regulator and 4-hydroxybenzoate permease, respectively. Furthermore, the BenR protein functions as a transcriptional activator of the ben operon, while transcription from the $c a t B C$ promoter can be activated in response to benzoate. Benzoate degradation is subject to carbon catabolite repression induced by glucose and acetate in A1501. The HPLC analysis of intracellular metabolites indicated that low concentrations of 4-hydroxybenzoate significantly enhance the ability of A1501 to degrade benzoate.
\end{abstract}

Conclusions: The expression of genes encoding proteins involved in the $\beta$-ketoadipate pathway is tightly modulated by both pathway-specific and catabolite repression controls in A1501. This strain provides an ideal model system for further study of the evolution and regulation of aromatic catabolic pathways.

\footnotetext{
* Correspondence: luwei0317@vip.sina.com; linmin57@vip.163.com

+ Contributed equally

${ }^{1}$ College of Biological Sciences, China Agricultural University, Beijing 100094,

China

${ }^{2}$ Biotechnology Research Institute, Chinese Academy of Agricultural Sciences,

Key Laboratory of Crop Biotechnology, Ministry of Agriculture, Beijing

100081, China
}

( Biomed Central (c) $2010 \mathrm{Li}$ et al; licensee BioMed Central Ltd. This is an Open Access article distributed under the terms of the Creative Commons Attribution License (http://creativecommons.org/licenses/by/2.0), which permits unrestricted use, distribution, and reproduction in any medium, provided the original work is properly cited. 


\section{Background}

Aromatic compounds, one of the most abundant classes of natural carbon compounds, accumulate primarily due to the degradation of plant-derived molecules (e.g., lignin). These structurally diverse compounds are independently converted to a small number of structurally simpler common intermediates, such as catechol and protocatechuate, which are subsequently metabolized to tricarboxylic acid intermediates via the $\beta$-ketoadipate pathway [1-3]. Therefore, many soil bacteria are characterized by considerable metabolic flexibility and physiological adaptability with a minimum number of functional proteins.

The $\beta$-ketoadipate pathway for degradation of aromatic compounds is widely distributed among bacteria. In addition, the microbial degradation of aromatic compounds has tremendous environmental significance. Therefore, the metabolic and genomic characteristics of the aromatic catabolic pathways from Acinetobacter, Pseudomonas, Geobacterter and Dechloromonas have been studied extensively [2,4-6]. For example, A. baylyi ADP1 (formerly known as Acinetobacter sp. ADP1) and P. putida KT2440 have long been used as a model for studying aromatic compound biodegradation and have contributed greatly to the elucidation of gene regulation of the $\beta$-ketoadipate pathway. In $A$. baylyi ADP1, the $\beta$-ketoadipate pathway consists of two parallel branches for the conversion of catechol and protocatechuate, which are derived from benzoate and 4-hydroxybenzoate, respectively [1]. At least 19 genes involved in the peripheral pathways for the catabolism of benzoate (ben) and 4-hydroxybenzoate $(p o b)$ and in the catechol (cat) and protocatechuate (pca) branches of the $\beta$-ketoadipate pathway have been identified in A. baylyi ADP1 [4]. P. putida KT2440 is another well-characterized bacterium capable of utilizing benzoate and 4-hydroxybenzoate [2,7-9]. Genome sequence analysis of strain KT2440 predicts the existence of the protocatechuate ( $p c a$ genes) and catechol (cat genes) branches of the $\beta$-ketoadipate pathway [2]. Further enzymatic studies and amino acid sequence data revealed that the $p o b, p c a$, ben and cat gene products are highly conserved in Acinetobacter and Pseudomonas strains. These products are usually synthesized in the presence of their respective substrates. Two different regulatory proteins, an XylS-type BenR in P. putida [9] and a LysR-type BenM in $A$. baylyi [10], are known to be involved in activating the ben gene expression in response to benzoate. In most cases, BenR/BenM is necessary for the ben expression but not for the expression of the cat genes, which can be regulated by CatR/CatM $[11,12]$. For example, BenR and CatR jointly activate more than a dozen chromosomal ben and cat genes responsible for benzoate catabolism in P. putida $[9,13]$. Thus, BenR-CatR or BenM-CatM regulation may serve as a practical model for complex regulatory circuits involved in the biodegradation of benzoate.

Aromatic compounds are not preferred as growth substrates. In most cases, synthesis of the catabolic enzymes is reduced when certain rapidly metabolizable carbon sources are simultaneously present [14]. One such control mechanism is called catabolite repression, which can integrate different signals, thus increasing the complexity of the system [15]. Although the molecular mechanism responsible for global control is not yet well understood, available data suggest that catabolite repression control $(\mathrm{Crc})$ is a component of a signal transduction pathway that modulates carbon metabolism in some soil bacteria. In addition, $\mathrm{Crc}$ has also been observed in several Pseudomonas species [16]. Very recently, A. baylyi Crc was proposed to be involved in determining the transcript stability of the pca-qui operon, thereby mediating catabolite repression [17].

The $\beta$-ketoadipate pathway is found almost exclusively in soil microorganisms, especially in Pseudomonas species, emphasizing the importance of aromatic compound catabolism in this family $[18,19]$. Establishment of the complete genome sequence of Pseudomonas strains enabled mapping of the entire catabolic gene cluster in their chromosomes $[2,20,21]$. Despite the current extensive knowledge about the aerobic catabolism of aromatic compounds in Pseudomonas strains, there remains much more to understand. For instance, the large information gap between sequence information and function for genes responsible for aromatic catabolism is a major challenge to the field of functional genomics. In particular, the evolutionary and regulatory mechanisms of aromatic catabolic pathways in the nitrogen-fixing and root-associated bacteria have been poorly documented. P. stutzeri A1501 was isolated from paddy soil in South China in the early 1980s for its ability to fix nitrogen under microaerobic conditions in the free-living state and to colonize rice endophytically [22-24]. As previously mentioned, aromatic compounds are highly abundant in the soil, so they can serve as a normal carbon source for A1501 when this bacterium colonizes on root surfaces of host plants. In this study, genomic analysis showed that A1501 contains sets of genes encoding enzymes and regulators involved in the biodegradation of benzoate and 4-hydroxybenzoate. Herein, we present evidence that benzoate degradation is subject to catabolite repression control. We also describe, for the first time, that low concentrations of 4-hydroxybenzoate significantly enhance the ability of A1501 to degrade benzoate. 


\section{Results}

Genome-wide analysis of the aromatic catabolism pathways

P. stutzeri has recently received particular attention for its metabolic properties, including denitrification, degradation of aromatic compounds, and nitrogen fixation. Since P. stutzeri A1501 was originally isolated from paddy soil and because it contains sets of genes for the $\beta$-ketoadipate pathway, it should be able to utilize aromatic compounds. In our study, we observed that this strain can aerobically degrade benzoate and 4-hydroxybenzoate. As the complete genome of P. stutzeri A1501 was sequenced recently [20], we mapped the genes encoding the peripheral pathways for the catabolism of 4-hydroxybenzoate $(p o b)$ and benzoate (ben) in the A1501 chromosome (Figure 1A). In many soil bacteria, these peripheral pathway enzymes channel the individual substrates into one of the two branches of the $\beta$ ketoadipate pathway, namely the catechol and protocatechuate branches. Sequence comparison indicated that A1501 has genes encoding all of the enzymes involved in the two branches of the $\beta$-ketoadipate pathway. The catechol (cat genes) and the protocatechuate branches ( $p c a$ genes) converge at $\beta$-ketoadipate enol-lactone. One set of enzymes, which are encoded by pcaDIJF, completes the conversion of $\beta$-ketoadipate enol-lactone to tricarboxylic acid cycle intermediates (Figure 1B).

In the A1501 genome, the cat genes are chromosomally linked with the ben genes and form an $11.5 \mathrm{~kb}$ supercluster (PST1666-PST1676). The deduced amino acid sequence of BenR in A1501 shows high similarity (61\% identity) to the P. fluorescens Pf-5 BenR protein. However, the $c a t R$ gene, which positively regulates the catBC and catA operons in other strains [12,25], is absent in A1501 (Figure 2A). Additionally, the pca genes in P. stutzeri A1501 are contiguous, whereas the pca genes are scattered over several portions of the genome in other Pseudomonas species, such as P. entomophila [21], P. aeruginosa [26], P. fluorescens [27] and $P$. putida [2] (Figure 2B). PcaR is an Icl family protein and has been reported to regulate most of the pca genes in the protocatechuate branch of the $\beta$-ketoadipate

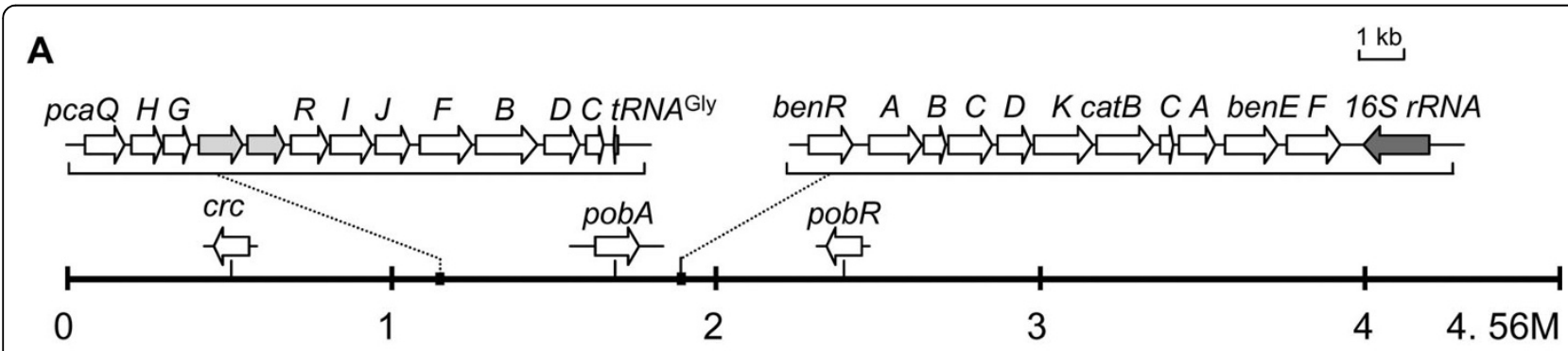

B

Regulated by BenR Inducible expression without CatR (?)

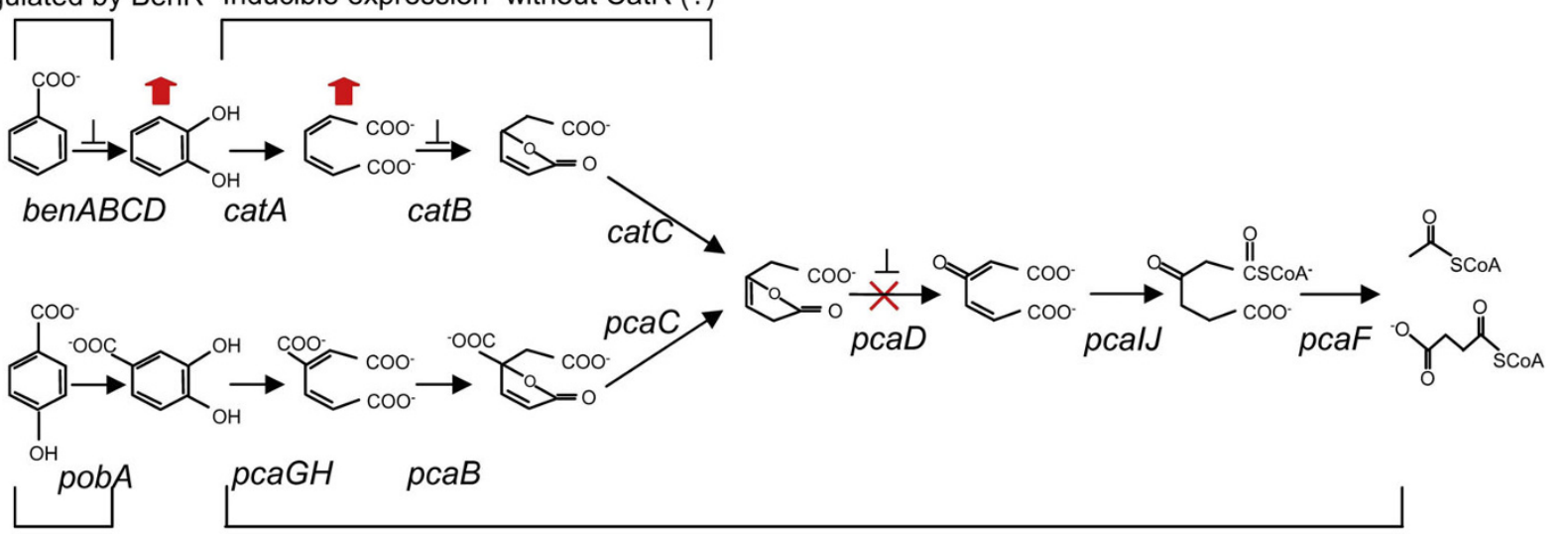

Regulated by PobR

Regulated by PcaQ or PcaR

Figure 1 The catechol and protocatechuate branches of the $\beta$-ketoadipate pathway and its regulation in $P$. stutzeri A1501. (A) Localization of the gene clusters involved in degradation of benzoate and 4-hydroxybenzoate on a linear map of the chromosome. (B) Predicted biochemical steps for the catechol and protocatechuate pathways in P. stutzeri A1501. The question mark indicates an unknown mechanism that may be involved in the regulation of cat genes. Inactivation of pcaD is shown by " $x$ " and accumulations of the intermediates catechol and cis, cis-muconate in the supernatants of the pcaD mutant are shown by red vertical arrows. Genes whose expression is under catabolite repression control $(\mathrm{Crc})$ are indicated by " $\perp$ ". 
pathway in $P$. putida $[12,28,29]$. In contrast to other Pseudomonas strains, pcaR is located immediately upstream of pcaI in A1501 (Figure 2B). The deduced amino acid sequence of A1501 PcaR shows $85 \%$ identity to that of P. putida KT2440. Notably, the pcaK gene, which encodes a 4-hydroxybenzoate permease responsible for 4-hydroxybenzoate transport [30], is absent in A1501 (Figure 2B). The catabolic gene organization in A1501 lacks the catR and $p c a K$ genes, a feature that is not observed in other Pseudomonas strains.
Functional characterization of the $\beta$-ketoadipate pathway A1501 grew well on $4 \mathrm{mM}$ benzoate and reached an $\mathrm{OD}_{600}$ of 0.5 after $24 \mathrm{~h}$ of incubation, whereas no growth was observed in the presence of $8 \mathrm{mM}$ benzoate. A1501 grow poorly on $0.4 \mathrm{mM}$ 4-hydroxybenzoate, while 4-hydroxybenzoate at concentrations above 0.8 $\mathrm{mM}$ completely inhibited bacterial growth (Figure 3 ). Further investigation of the $\beta$-ketoadipate pathway was made by constructing and characterizing three mutants: benR mutant A1601, pcaR mutant A1602 and pcaD

A

P. stutzeri $\mathrm{A} 1501$

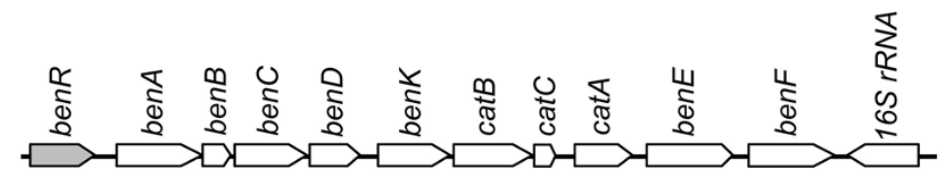

$P$. aeruginosa $\mathrm{PAO} 1$

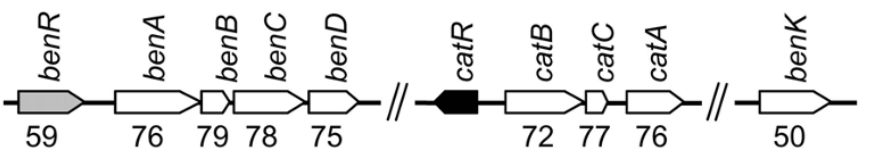

P. putida KT2440

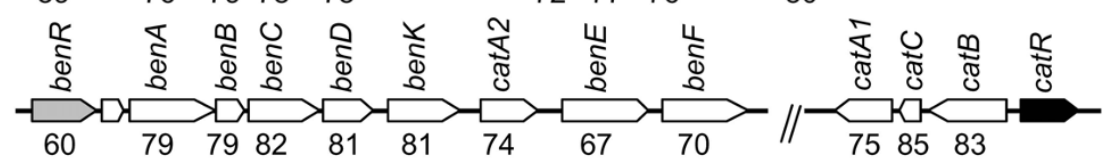

P. fluorescens Pf-5

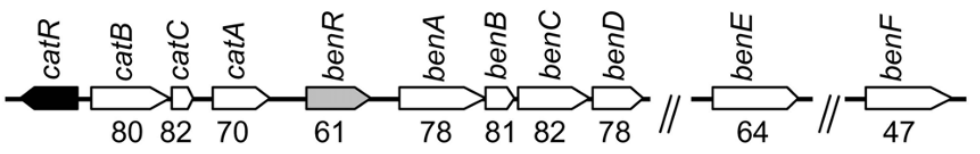

A. baylyi ADP1

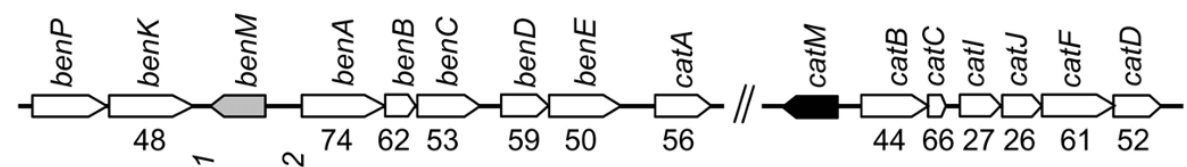

B

P. stutzeri A1501

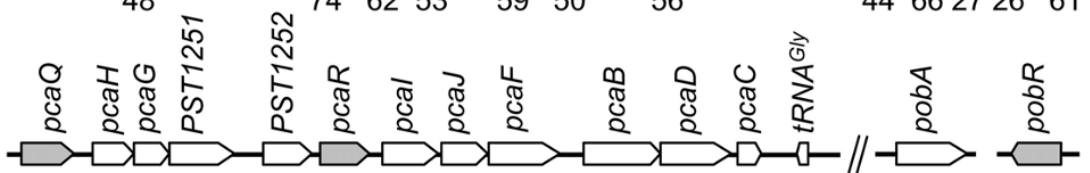

P. aeruginosa PAO1
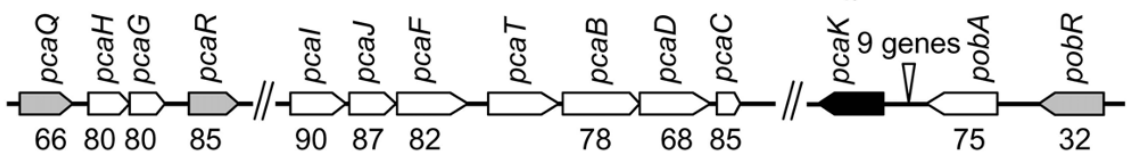

P. putida KT2440
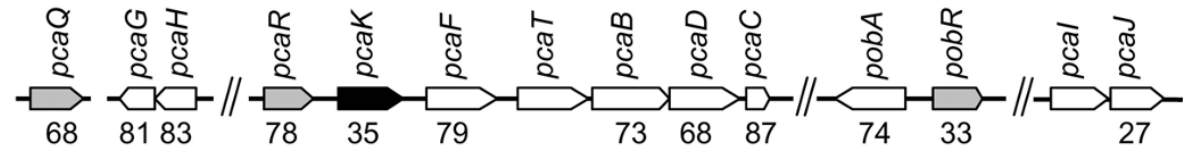

P. fluorescens Pf-5

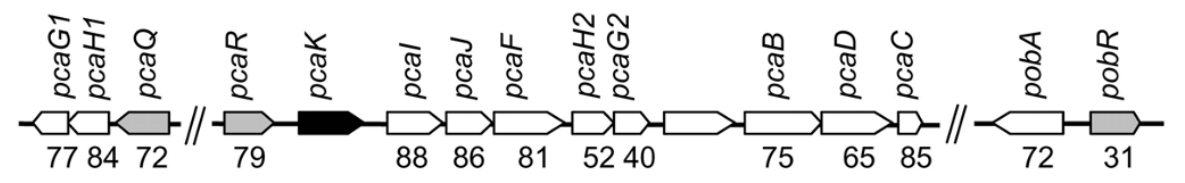

A. baylyi ADP1

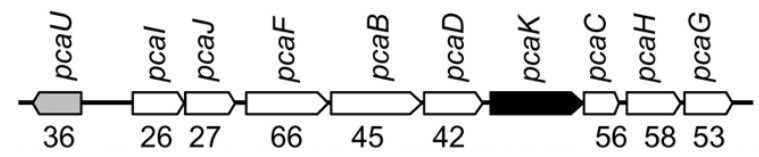

Figure 2 Organization of benzoate (A) or 4-hydroxybenzoate (B) degradation gene clusters of A1501 and comparison with equivalent clusters from other bacteria. Two vertical lines indicate that the genes are not adjacent in the genome. Numbers beneath the arrows indicate the percentage of amino acid sequence identity between the encoded gene product and the equivalent product from A1501. 
mutant A1603 (Table 1). When the wild type and mutants were cultured in media containing lactate, their growth rates were not affected (data not shown). As expected, the benR mutant failed to grow on benzoate, and the pcaR and pcaD mutants failed to grow on 4-hydroxybenzoate as the sole carbon source. Furthermore, both the $p c a R$ and $p c a D$ mutants lost their ability to utilize benzoate as a carbon source. We constructed three complementary plasmids containing the entire $p c a D, p c a R$ and benR genes for further growth complementation assays. Complementation of the three mutants with the corresponding complementary plasmids restored the catabolic activity, and the three corresponding complementary strains grew on benzoate as the sole carbon source (data not shown). Results from gene disruption analyses and genetic complementation tests demonstrate that the three genes are required for the growth of A1501 on benzoate.

High-performance liquid chromatography (HPLC) was used to measure the concentrations of catechol and muconate in the culture supernatants of the wild type A1501 and pcaD mutant A1603 grown on benzoate as the sole carbon source (Figure 4; see Additional file 1). During the initial phase of benzoate catabolism by A1501, small amounts of catechol $(\sim 30 \mu \mathrm{M})$ and cis, cismuconate $(\sim 500 \mathrm{nM})$ were detected. After $24 \mathrm{~h}$, benzoate was completely removed from the culture supernatants, and no metabolites could be detected (see Additional file 1). The inability of the pcaD mutant
A1603 to grow on benzoate was further confirmed by HPLC analysis of culture supernatants. After $48 \mathrm{~h}$, the concentration of benzoate remained almost unchanged in the culture supernatant of the mutant, while accumulation of catechol and cis, cis-muconate was detected by HPLC (Figure 4). As shown in Figure 1B, inactivation of PcaD completely blocked the conversion of $\beta$-ketoadipate enol-lactone to $\beta$-ketoadipate, resulting in accumulation of the intermediates catechol and cis, cismuconate derived from benzoate. These results provide experimental evidence that the two branches of the $\beta$ ketoadipate pathway converge at $\beta$-ketoadipate enol-lactone and that the products of pcaDIJF complete the conversion of the latter to TCA cycle intermediates in P. stutzeri A1501, as documented in other Pseudomonas strains [2].

As mentioned above, A1501 can grow well on benzoate, but not on 4-hydroxybenzoate, as the sole carbon and energy source. Therefore, we focused on the genetic organization of the A1501 ben-cat region. As shown in Figure 5A, nine ben and cat genes are in the same transcriptional orientation and the lengths of the intergenic regions vary. Gene expression was further studied by amplifying intergenic regions between adjacent genes. Eight pairs of oligonucleotide primers were designed (Table 2). As shown in Figure 5B, in the presence of benzoate, four products of their expected sizes were amplified with the PF/PR primer pairs spanning the borders of benA-benB (456 bp), benB-benC (503 bp), benC-

Table 1 Strains and plasmids used in this study

\begin{tabular}{|c|c|c|}
\hline Strains or plasmids & Relevant characteristic(s) $^{\mathrm{a}}$ & Source or reference \\
\hline \multicolumn{3}{|l|}{ Strains } \\
\hline \multicolumn{3}{|l|}{ P. stutzeri } \\
\hline A1501 & Wild type, Chinese culture CGMCC 0351, Ben ${ }^{++}, \mathrm{Cat}^{++}, 4 \mathrm{HBA}^{+}$ & \\
\hline A1601 & A1501 benR::pK18mob $\Delta$ benR, Ben ${ }^{-} \mathrm{Cat}^{++}, 4 \mathrm{HBA}^{+}$ & this study \\
\hline A1602 & A1501 pcaR::pK18mob $\Delta p c a R$, Ben $^{-}$, Cat $^{-}, 4 \mathrm{HBA}^{-}$ & this study \\
\hline A1603 & A1501 pcaD::pK18mob $\Delta p c a D, B^{-}{ }^{-}$, Cat, $4 \mathrm{HBA}^{-}$ & this study \\
\hline A1608 & A1601 harboring complement plasmid pLbenR & this study \\
\hline A1609 & A1602 harboring complement plasmid pLpcaR & this study \\
\hline A1610 & A1603 harboring complement plasmid pLpcaD & this study \\
\hline \multicolumn{3}{|l|}{ Plasmids } \\
\hline pK18mob & $\mathrm{Km}^{\mathrm{r}}$; oriColE1 $\mathrm{Mob}^{+}$lac $Z \alpha^{+}$, used for directed insertional disruption & \\
\hline pRK2013 & $\mathrm{Km}^{\mathrm{r}}$; $\mathrm{Tra}^{+}$, oriColE1 & \\
\hline pLAFR3 & Tcr; Tra-, Mob+, cos, RK2 replicon & \\
\hline pkbenR & $\mathrm{Km}^{\mathrm{r}} ; 293 \mathrm{bp}$ EcoR I-Hind III fragment containing part of benR in pK18mob & this study \\
\hline pKpcaR & $\mathrm{Km}^{\mathrm{r}} ; 299 \mathrm{bp}$ EcoR I-Hind III fragment containing part of pcaR in pK18mob & this study \\
\hline pKpcaD & $\mathrm{Km}^{\mathrm{r}} ; 361 \mathrm{bp}$ EcoR I-Hind III fragment containing part of pcaD in pK18mob & this study \\
\hline pLbenR & TCr; 1041 bp EcoR I-Hind III fragment containing benR with its native promoter in pLAFR3 & this study \\
\hline pLpcaR & Tcr; 1457 bp EcoR I-Hind III fragment containing pcaR with its native promoter in pLAFR3 & this study \\
\hline pLpcaD & $\mathrm{Tc}^{\mathrm{r}} ; 820 \mathrm{bp}$ EcoR I-Hind III fragment containing pcaD with the lac promoter in pLAFR3 & this study \\
\hline
\end{tabular}

${ }^{\mathrm{a}} \mathrm{Ben}^{++}$, good growth on benzoate; $\mathrm{Cat}^{++}$, good growth on catechol; $4 \mathrm{HBA}^{+}$, weak growth on 4-hydroxybenzoate; Ben', no growth on benzoate; Cat', no growth on catechol; $4 \mathrm{HBA}^{-}$, no growth on 4-hydroxybenzoate; $\mathrm{Km}^{r}$, kanamycin resistant; $\mathrm{Tc}^{\mathrm{r}}$, tetracycline resistant. 


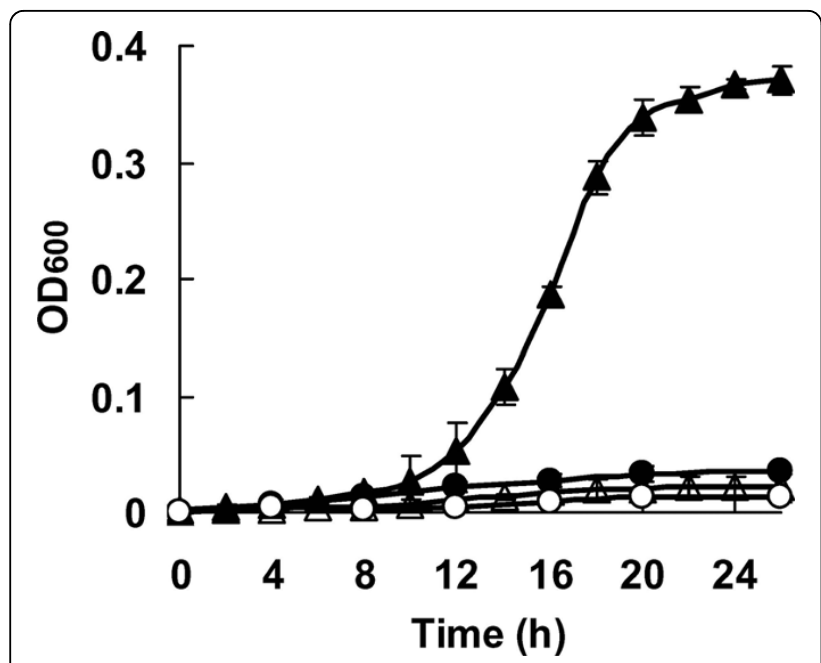

Figure 3 Bacterial growth of A1501 cultured in minimal medium containing $4 \mathrm{mM}$ benzoate (black triangle), $8 \mathrm{mM}$ benzoate (clear triangle), $0.4 \mathrm{mM}$ 4-hydroxybenzoate (black dot) or $0.8 \mathrm{mM}$ 4-hydroxybenzoate (clear dot).

benD (546 bp), and catB-catC (309 bp). No PCR products were observed with the PF/PR primer pairs spanning the borders of benR-benA (782 bp), benD-benK (610 bp), benK-catB (1074 bp), and catC-catA (1030 bp) in the presence or absence of benzoate. These results suggest that nine benzoate metabolic genes are organized in five transcriptional units. In particular, the cat $B C$ genes are co-transcribed in the presence of benzoate.

\section{BenR activates expression of the ben $A B C D$ operon in responseto benzoate}

In pseudomonads, benzoate catabolism is initiated by the benABCD operon encoding benzoate dioxygenase

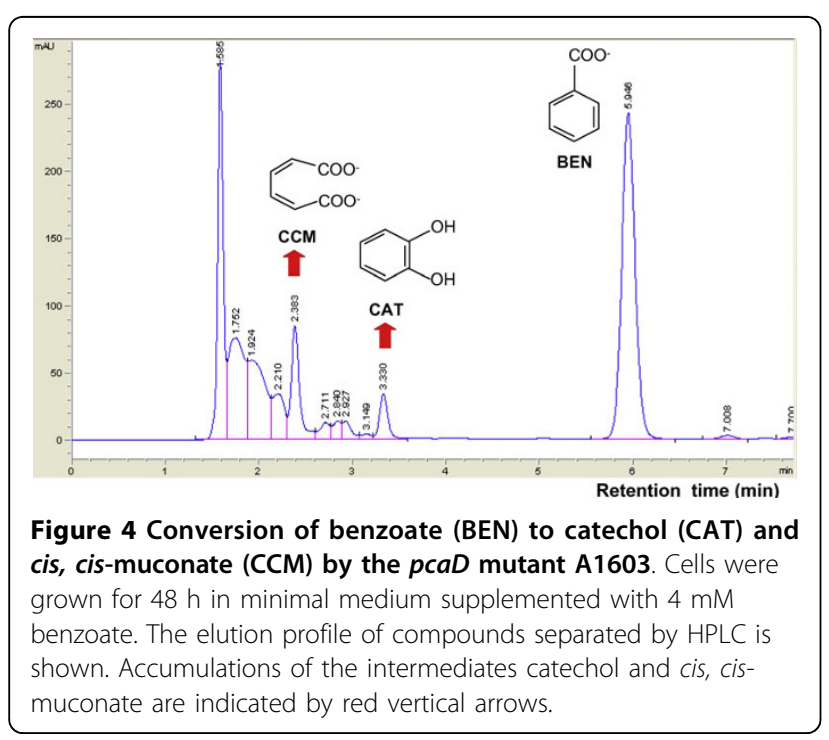

(BenABC) and 2-hydro-1,2-dihydroxybenzoate dehydrogenase $(\mathrm{BenD})$, whose expression is positively regulated by BenR [9,31]. In this study, we found that disruption of the benR gene resulted in a simultaneous loss of the ability to utilize benzoate, but this mutant could grow on catechol, suggesting that BenR might be the sole activator of expression of benABC in A1501. To confirm this, we searched the promoter sequence of $\operatorname{ben} A$ using in silico analysis. The nucleotide sequence upstream of the ben $A B C D$ operon has the following sequence features: a putative -10/-35-type promoter, a putative BenR-binding region, and a predicted translational start site (Figure 6A). Comparison with the experimentally well-characterized BenR-binding sequences in P. putida [9] indicated a highly conserved BenR site in the promoter region of the A1501 benA gene (Figure 6A). To determine whether benR is required for activation of the

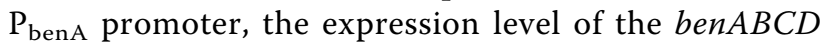
operon was tested in the benR mutant A1601. Quantitative real-time PCR results demonstrated that a significant increase in transcription from the $P_{\text {benA }}$ promoter was seen in wild-type A1501 when benzoate was included in the growth medium, whereas the addition of catechol or cis,cis-muconate had a very weak effect (Figure 6B). When BenR was absent, transcription from the $\mathrm{P}_{\text {benA }}$ promoter was highly repressed, irrespective of the presence or absence of the inducer (Figure 6B). As reported in P. putida [9], these results led us to conclude that the ben $A B C D$ operon is under the control of BenR in response to benzoate in A1501.

\section{Benzoate-mediated induction of the catBC operon in A1501}

In $P$. putida, the cat $B C$ operon encodes cis,cis-muconate lactonizing enzyme I ( $\mathrm{CatB}$ ) and muconolactone isomerase (CatC), which catalyze the second and third steps of the catechol branch of the $\beta$-ketoadipate pathway, respectively [8]. The transcription of this operon requires CatR and cis,cis-muconate [32]. Additionally, the translational starts of $c a t R$ and $c a t B C$ are separated by 136 bp of intervening DNA containing -35/-10-type promoters and the CatR-binding sites in $P$. putida $[13,33]$. However, we found that only 29 nucleotides are present in the noncoding regions between benK and $c a t B$ in A1501, suggesting that the promoter region of the $c a t B C$ operon overlaps with the coding region of the $b e n K$ gene. The promoter region of the cat $B C$ operon from A1501 shows very low similarity to those of the three other Pseudomonas strains, notably the lack of the typical binding site for CatR present in the $c a t B$ promoter region of other Pseudomonas strains (Figure 6C). Although a catR orthologue could not be identified in A1501, quantitative real-time PCR experiments indicated that benzoate has the strongest 
Table 2 Primers for RT-PCR and Quantitative Real Time RT-PCR

\begin{tabular}{|c|c|c|c|}
\hline Primer No. & Primer name & Sequence $\left(5^{\prime}-3^{\prime}\right)$ & Amplified fragment $^{\mathrm{a}}$ \\
\hline 1 & RT1-5' & AGCGAGAACCAATGGC & $782 \mathrm{bp}$ benRA intergenic region \\
\hline 2 & $\mathrm{RT} 1-3^{\prime}$ & TAGTCGATTCCCAGGG & \\
\hline 3 & RT2-5' & GCACTGGATCGAGGGAGC & $456 \mathrm{bp}$ ben $A B$ intergenic region \\
\hline 4 & RT2-3' & GTTGTGCGAGGTGCGTGT & \\
\hline 5 & RT3-5' & GCTTTCGCTACAAGACCG & $503 \mathrm{bp}$ ben $B C$ intergenic region \\
\hline 6 & RT3-3' & CGCACGTTGCTGATGGTC & \\
\hline 7 & RT4-5' & CGAACCCAAACACCTCAA & 546 bp benCD intergenic region \\
\hline 8 & RT4-3' & CTCGGCCTCGATCTCATG & \\
\hline 9 & RT5-5' & TACCAGGAACATGAGAT & $610 \mathrm{bp}$ benDK intergenic region \\
\hline 10 & RT5-3' & ACGTCTACTITTCGCATG & \\
\hline 11 & RT6-5' & GTTCTTCTGTTGCCTG & 1074 bp benK and catB intergenic region \\
\hline 12 & RT6-3' & TCTTCGATGTCCTTAG & \\
\hline 13 & RT7-5' & CCTTCGTCACCCTCAACA & 309 bp catBC intergenic region \\
\hline 14 & RT7-3' & CTTCACGCATCAGGCTCT & \\
\hline 15 & RT8-5' & GAAGATGATCGTGAAAC & 1030 bp catCA intergenic region \\
\hline 16 & RT8-3' & TGAAGAAATGAATGTGC & \\
\hline 17 & benA-5' & CGGCTCGTCCACCTATGTCTAT & $186 \mathrm{bp}$ internal fragment \\
\hline 18 & benA-3' & AAACCACCGCCCTTCTTGC & \\
\hline 19 & catB-5' & CCTTCGTCACCCTCAACAG & $159 \mathrm{bp}$ internal fragment \\
\hline 20 & catB-3' & TCCAGGCTCAGGCCAAGAC & \\
\hline 21 & pcaD-5' & TTCGCCGAGCATTTCCG & $173 \mathrm{bp}$ internal fragment \\
\hline 22 & pcaD-3' & CCGATCAGTCCGCCCAT & \\
\hline
\end{tabular}

PCR reactions were carried out with the sets of primers indicated to the left.

induction effect on expression of the catBC operon (Figure 6D). Since benzoate induces expression of catB in the benR mutant background and this mutant is unable to metabolize benzoate, we proposed that induction of the $c a t B C$ expression is not due to the production of benzoate metabolites, such as cis,cismuconate. As reported in P. putida, induction of the cat $B C$ operon requires cis,cis-muconate, an intermediate of benzoate degradation, and CatR, a well-studied activator in the $\beta$-ketoadipate pathway [32]. However, benzoate itself has a significant induction effect on expression of the catBC operon in A1501, strongly suggesting the existence of an uncharacterized regulatory mechanism.

\section{Benzoate degradation in A1501 is subject to carbon catabolite repression}

In Pseudomonas and Acinetobacter strains, the Crc global regulator controls the expression of genes involved in benzoate degradation when other preferred carbon sources are present in the culture medium $[16,17]$. Based on sequence comparison, we found a Crc-like protein in the A1501 genome (Figure 1A). The A1501 Crc-like protein shows highest amino acid identity with P. aeruginosa $\mathrm{Crc}$ (86\%), whereas relatively low amino acid identity (only 38\%) is observed between A1501 and A. baylyi Crc proteins.

Benzoate degradation by A1501 involves the oxidation of benzoate into catechol in a two-step process catalyzed by BenABC and BenD, two peripheral pathway enzymes of the catechol pathway. The catechol aromatic ring is converted by the action of CatA, CatB and CatC to cis, cis-muconate, and then to $\beta$-ketoadipate-enol-lactone, which is transformed into acetyl-CoA and succinyl-CoA by PcaD, PcaIJ, and PcaF from the $\beta$-ketoadipate pathway. Therefore, the $\operatorname{ben} A, \operatorname{cat} B$, and $p c a D$ genes were selected for further analysis. In the presence of the inducer benzoate, highly significant differences in expression were observed, depending on the nature of the noninducing carbon source (Figure 7). The expression of the three selected genes was most efficiently induced by benzoate when cells were grown on lactate and succinate alone, but was decreased significantly when the carbon source was glucose or acetate (Figure 8). When cells grew on lactate, the expression of benA and catB was efficiently induced by benzoate, respectively; when glucose plus succinate was used as the carbon source, induction was significantly lower (Figure 7A, B). The ben $A$ and $c a t B$ genes showed a similar repression pattern to the $p c a D$ gene, with the slight difference being 
A

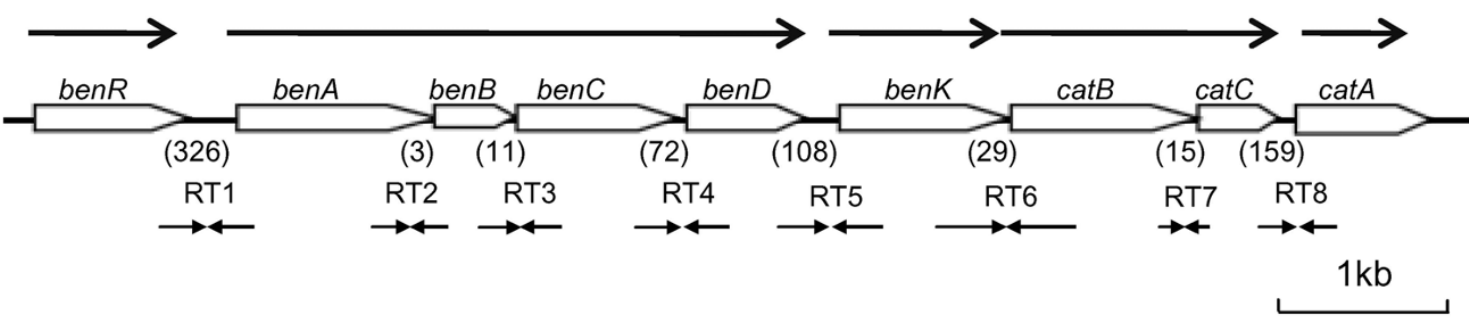

B
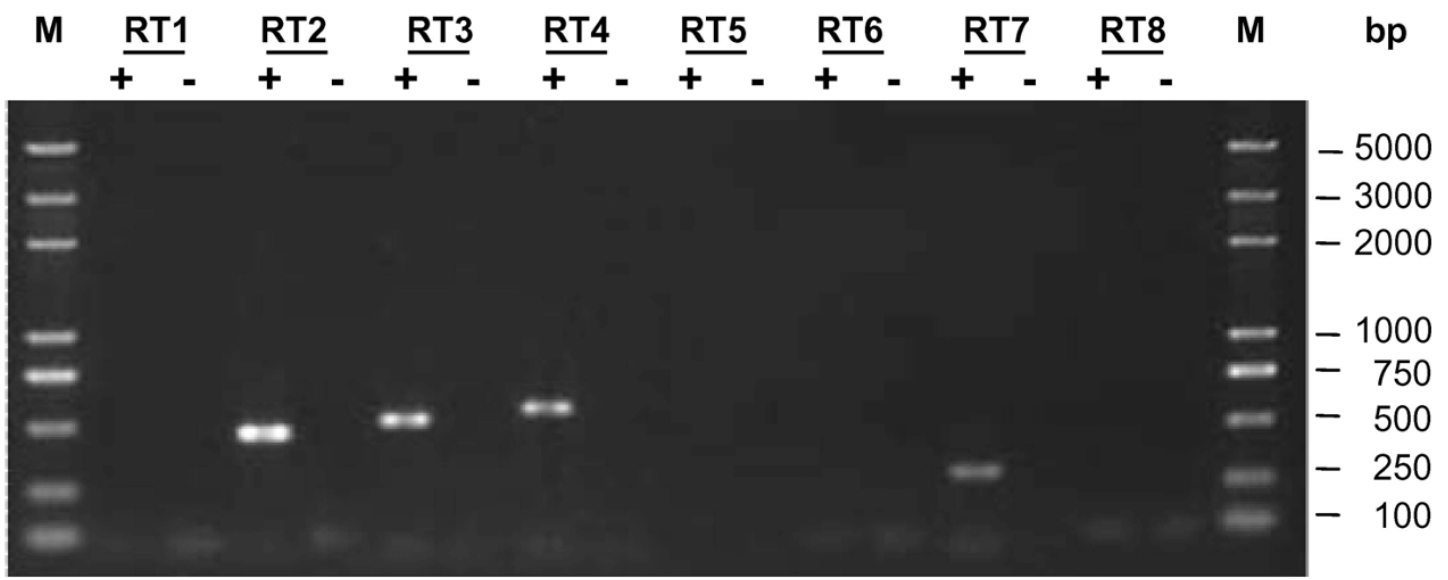

Figure 5 Transcriptional organization of the chromosomal ben-cat region. (A) The number of nucleotides in noncoding regions is shown in parentheses. Transcriptional units and directions are denoted by horizontal arrows in the upper panel. The designation and location of primers used for RT-PCR are in the lower panel. A pair of oligonucleotide primers is marked with a convergent arrow. (B) RT-PCR analysis of mRNA transcripts using gel electrophoresis of amplified cDNA fragments. The first and last lanes were loaded with molecular size markers. +, in the presence of inducer benzoate; -, in the absence of inducer benzoate.

that acetate was an intermediate-repressing carbon source. Using glucose or succinate as individual carbon sources led to a strong decreasing or increasing effect on expression of the pcaD gene, respectively, whereas growth on a combination of glucose plus succinate and inducer resulted in high induction (Figure 7C). These results suggest that benzoate degradation in A1501 is subject to carbon catabolite repression. Our experimental evidence, combined with the identification of the Crc-like protein in A1501, may be indicative of distinct activities of $\mathrm{Crc}$ at different genes or in various bacteria, as previously shown in $A$. baylyi and $P$. putida $[34,35]$. Further experiments are required to construct an A1501 mutant lacking the Crc-like protein and to investigate role of this protein in carbon catabolite repression.

\section{4-hydroxybenzoate enhances the ability of A1501 to degrade benzoate}

A study reported that high concentrations of aromatic hydrocarbons are harmful to cells because they disrupt membrane components [36]. In the plate assay, A1501 grew extremely poorly on 4-hydroxybenzoate as the sole carbon source with colonies of less than $1.0 \mathrm{~mm}$ in diameter after 3 days, whereas it produced normal-sized colonies $(>5 \mathrm{~mm})$ on benzoate alone in the same period. These results indicate that 4-hydroxybenzoate itself directly inhibits A1501 growth, which is likely caused by the toxicity of 4-hydroxybenzoate. It is unclear whether the lack of pcaK results in the loss of 4-hydroxybenzoate transport, leaving A1501 unable to metabolize 4-hydroxybenzoate efficiently. In subsequent experiments, growth of A1501 was examined in a mixture of $4 \mathrm{mM}$ benzoate and $0.4 \mathrm{mM}$ 4-hydroxybenzoate. A1501 showed a shorter lag phase and a higher growth rate when cells were grown on the mixture than when benzoate was supplied alone (Figure 8A). Furthermore, under the latter growth conditions, the culture gradually became dark brown in color because of autoxidation of the accumulated catechol (data not shown). However, when the 4-hydroxybenzoate concentration increased to $0.8 \mathrm{mM}$, growth of A1501 was completely inhibited (Figure $8 \mathrm{~A}$ ). These results indicate that 4-hydroxybenzoate at low concentrations can enhance the ability of A1501 to grow on benzoate.

We then evaluated the effect of 4-hydroxybenzoate on the metabolism of benzoate using HPLC. When $4 \mathrm{mM}$ benzoate alone was provided to the culture, it was 


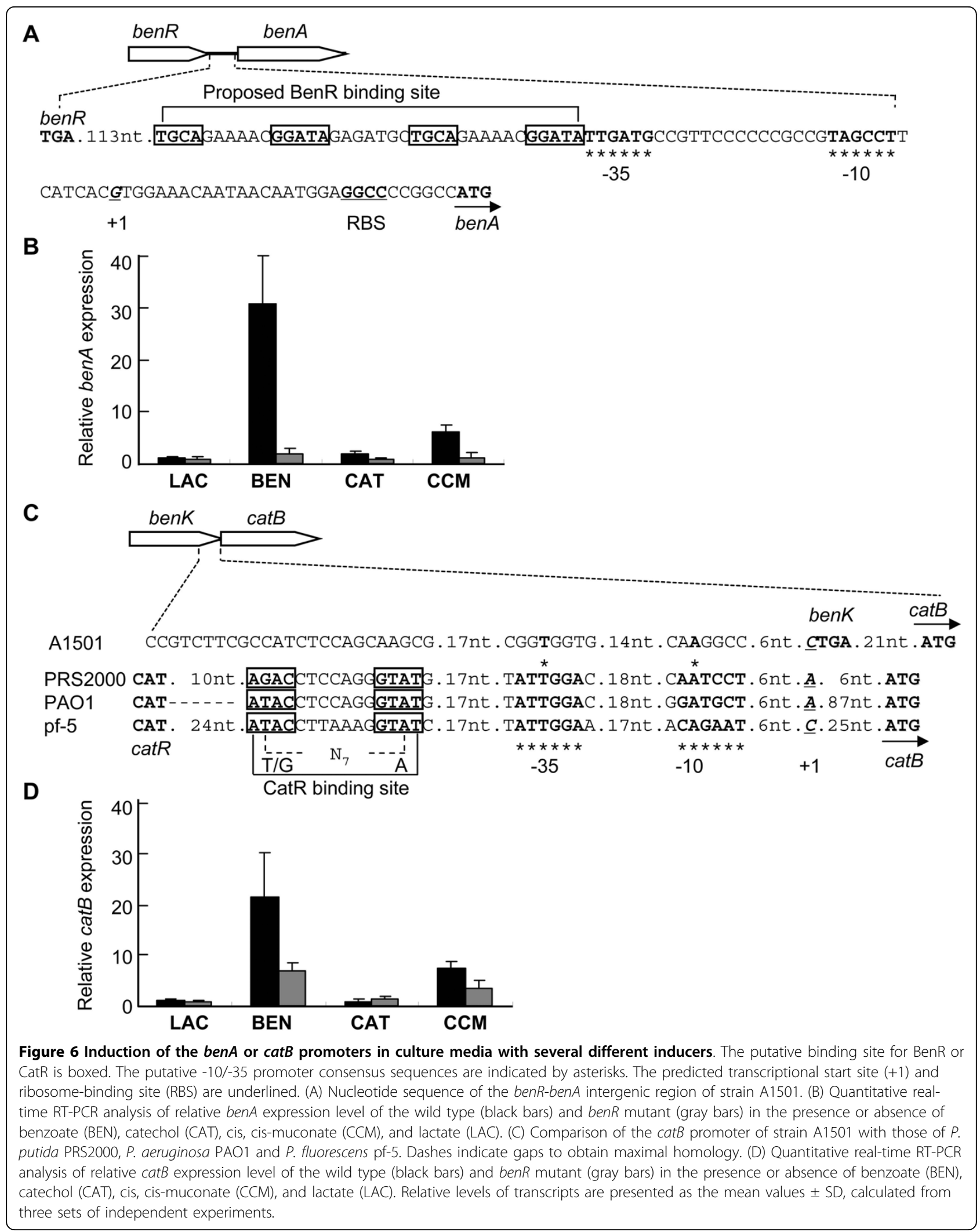




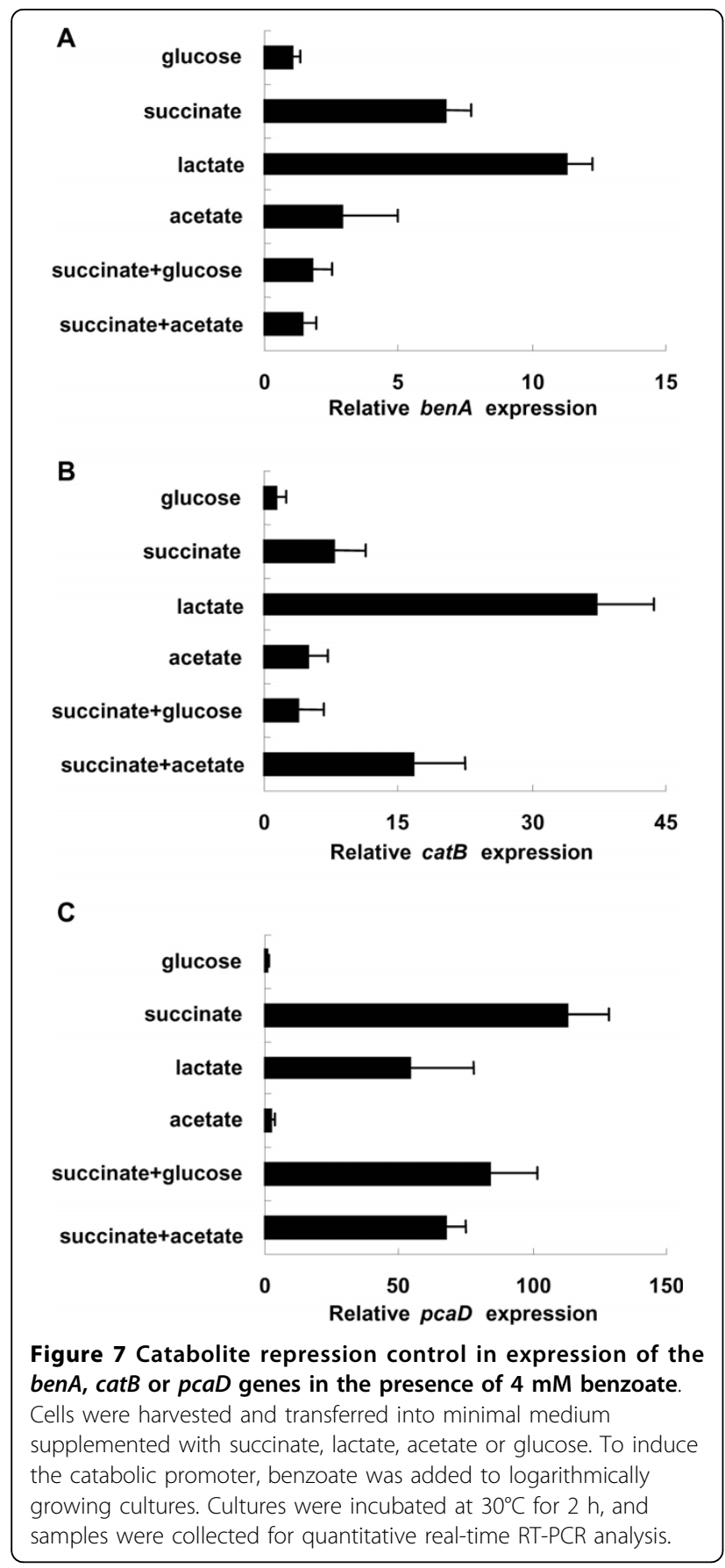

completely consumed within $26 \mathrm{~h}$, and metabolic intermediates were present. When $4 \mathrm{mM}$ benzoate and 0.4 $\mathrm{mM}$ 4-hydroxybenzoate were provided together as growth substrates, benzoate was completely consumed within $18 \mathrm{~h}$, while no discernible loss of 4-hydroxybenzoate was detected (Figure 8B). Additionally, analysis of the intracellular metabolites by HPLC revealed accumulation of catechol derived from benzoate both in the presence and absence of 4-hydroxybenzoate in the
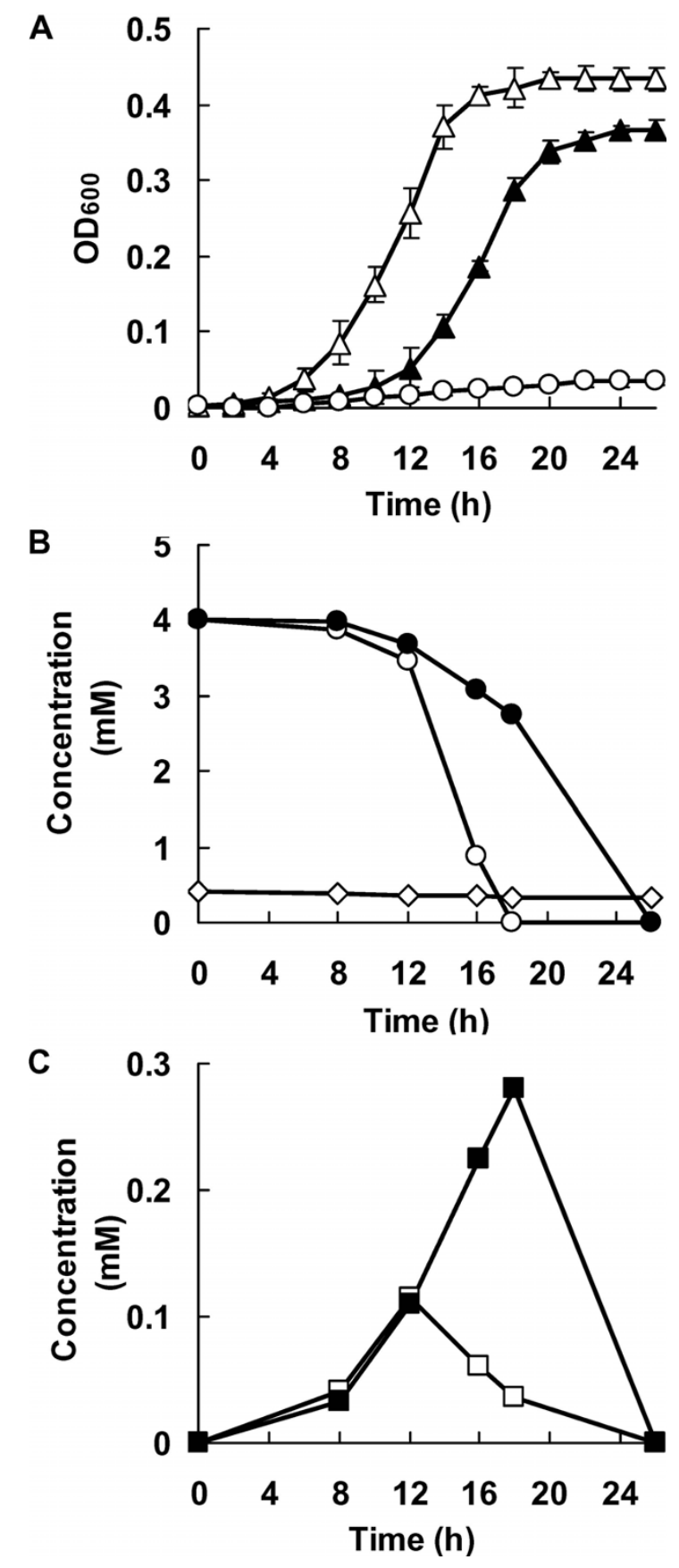

Figure 8 The enhanced ability of A1501 to degrade benzoate by 4-hydroxybenzoate. (A) Time course of bacterial growth in the presence of $4 \mathrm{mM}$ benzoate (black triangle) or a mixture of $4 \mathrm{mM}$ benzoate and $0.4 \mathrm{mM}$ (clear triangle) or $0.8 \mathrm{mM}$ (clear dot) 4hydroxybenzoate. (B) The benzoate consumption when A1501 was cultured in minimal medium containing $4 \mathrm{mM}$ benzoate (black dot) or a mixture of $4 \mathrm{mM}$ benzoate and $0.4 \mathrm{mM}$ 4-hydroxybenzoate (clear dot), and changes in 4-hydroxybenzoate concentrations (clear diamond) were detected by HPLC. (C) The formation of catechol derived from benzoate (black square) or a mixture of benzoate and 4-hydroxybenzoate (clear square). Samples were collected at different times and the amount of the aromatic compound in the culture supernatant was determined by HPLC. 
growth medium. The concentration of catechol reached $0.28 \mathrm{mM}$ when A1501 grew on benzoate alone, whereas the concentration of catechol reached approximately $0.12 \mathrm{mM}$ when both benzoate and 4-hydroxybenzoate were in the growth medium (Figure 8C). Collectively, these results suggest that 4-hydroxybenzoate can significantly enhance the ability of A1501 not only to degrade benzoate, but also to remove the catechol accumulated from benzoate.

\section{Discussion}

The data presented here reveal that the sequence and organization of the ben, pob, cat, and pca genes in A1501 are very similar to those within other well-studied Pseudomonas strains, raising the question of whether these genes have common origins. Increasing evidence indicates that horizontal gene transfer is an efficient mechanism for introducing catabolic pathways into different bacterial genomes [37]. In general, recently acquired transferable genomic regions are associated with insertion sequence elements and mobility-related genes, whereas anciently acquired genomic regions may lose these genetic elements [38]. Furthermore, horizontally acquired DNA regions are usually chromosomally inserted in the vicinity of tRNA or rRNA genes [38]. We also discovered that an rRNA operon is located directly downstream of the ben gene cluster and that a tRNA-Gly gene is located downstream of the $p c a$ gene cluster. Although insertion sequence elements and mobility-related genes are absent, the packing of the catabolic pathway genes as well as the difference in the $\mathrm{G}+\mathrm{C} \%$ content from the rest of the genome favor the hypothesis that the $\beta$-ketoadipate pathway in A1501 is acquired from horizontal gene transfer, which contributes to an increased adaptability in the soil environment.

As shown in Figure 2, the gene arrangement of the ben, cat, and pca clusters differs between different bacteria. Apparently, various DNA rearrangements have occurred during its evolution in each particular host. Furthermore, we observed the lack of the catR and pcaK genes, a distinguishing feature of the catabolic gene organization in A1501, suggesting that gene deletion events responsible for the loss of the two genes have occurred over a long period of evolution. In most cases, the complex regulatory circuits involving the two sets of transcriptional regulators, BenR/BenM and CatR/CatM, have evolved to allow optimal expression of catabolic genes $[39,40]$. Unlike $P$. putida in which the transcription of the catBC operon requires CatR and cis,cismuconate [32], we could not identify a cat $R$ orthologue or a consensus sequence typical of CatR-dependent promoters in A1501. In particular, benzoate, but not cis,cismuconate, has a significant induction effect on the expression of the catBC operon in A1501. Therefore, we propose that an uncharacterized regulatory mechanism might be involved in the regulation of the $\beta$-ketoadipate pathway in A1501, but this hypothesis requires further investigation.

A1501 contains all of the enzymes involved in the 4hydroxybenzoate degradation pathway. However, this strain shows extremely poor growth on 4-hydroxybenzoate as the sole carbon source. A plausible explanation for this observation is due to the lack of PcaK, a 4hydroxybenzoate transporter, thereby leaving A1501 unable to metabolize 4-hydroxybenzoate efficiently. In most cases, the pcaK mutation had a negative effect on bacterial 4-hydroxybenzoate uptake and growth. For example, mutants blocked in 4-hydroxybenzoate transport have been identified in two biovars of Rhizobium leguminosarum [41]. Growth of these mutants was completely blocked when cultured on 4-hydroxybenzoate. By contrast, growth of the $P$. putida pcaK mutant was not significantly impaired on 4-hydroxybenzoate at neutral $\mathrm{pH}$ [30]. Furthermore, repression of 4-hydroxybenzoate transport and degradation by benzoate has been reported in P. putida [42]. Unexpectedly, our results indicate that low concentrations of 4-hydroxybenzoate significantly enhance the ability of A1501 to degrade benzoate, potentially due to 4-hydroxybenzoatemediated induction of enzymes, such as $\mathrm{PcaD}$, required for dissimilation of benzoate by the $\beta$-ketoadipate pathway. Pesticides and industrial wastes often contain aromatic constituents, including many that are toxic to living organisms. The degradation of aromatic compound mixtures has recently received a great deal of attention. To our knowledge, this is the first report of enhanced benzoate degradation by 4-hydroxybenzoate, highlighting its potential physiological significance. The metabolic capacity for utilizing different aromatic compounds as carbon or energy sources confers a selective advantage, notably for exposure to a mixture of aromatic compounds. The findings obtained from this study will help to investigate novel regulatory mechanisms and catabolic activities that can be of great biotechnological interest for improving the microbial degradation of aromatic environmental pollutants.

\section{Conclusions}

We have shown that A1501 contains sets of genes encoding enzymes and regulators responsible for the entire benzoate or 4-hydroxybenzoate-degrading pathways. The unique features found in the A1501 catabolic pathway are not just rearrangements of structural genes but represent the existence of an uncharacterized regulatory mechanism and the lack of CatR, a well-studied activator in other benzoate-degrading bacteria. We also described for the first time that low concentrations of 4- 
hydroxybenzoate significantly enhance the ability of A1501 to degrade benzoate. More extensive studies are needed to fully understand mechanisms involved in the regulation of cat genes and to further improve the ability of A1501 to degrade aromatic environmental pollutants.

\section{Methods}

\section{Bacterial strains, plasmids and growth conditions}

The bacterial strains and plasmids used in this work are listed in Table 1. Bacterial strains were grown in LuriaBertani (LB) and minimal lactate-containing medium (medium K), as previously described [43]. When required, carbon sources were supplemented at the following final concentrations: $4 \mathrm{mM}$ glucose, $4 \mathrm{mM}$ succinate, $4 \mathrm{mM}$ lactate, $4 \mathrm{mM}$ acetate, $4 \mathrm{mM}$ benzoate, 0.4 $\mathrm{mM}$ catechol and $0.4 \mathrm{mM}$ 4-hydroxybenzoate. The following antibiotics were added as required at the indicated final concentrations: $10 \mu \mathrm{g} / \mathrm{ml}$ tetracycline (Tc) and $50 \mu \mathrm{g} / \mathrm{ml}$ kanamycin $(\mathrm{Km})$.

\section{Construction of nonpolar mutants}

We constructed a nonpolar insertion into the benR, $p c a R$, and pcaD genes, respectively, by homologous suicide plasmid integration, as described previously [44], using pK18mob as the vector [45]. DNA fragments ( $300 \mathrm{bp})$ were amplified using the total DNA of A1501 as the template and appropriate oligonucleotide primers. Oligonucleotide primers were designed to generate amplicons for the creation of nonpolar mutations enabling transcription of downstream genes. The amplicons were ligated into the vector pK18mob and the resulting plasmids were introduced into $P$. stutzeri A1501 from Escherichia coli JM109 by triparental conjugation using pRK2013 [46] as the helper plasmid. The nonpolar mutant strains A1601, A1602, and A1603 were generated in which benR, pcaR, and pcaD, respectively, were disrupted without blocking the transcription of downstream genes. Correct recombination was confirmed by PCR analysis. For further growth complementation assays, we used the broad host vector pLAFR3 to construct three complementary plasmids, pLbenR, pLpcaD and pLpcaR, as described previously [47]. Three complementary plasmids and the corresponding complementary strains are listed in Table 1.

\section{RT-PCR and Quantitative real-time PCR}

Total RNA was isolated with an SV Total RNA Isolation System (Promega, Madison, WI, USA) and treated with RNase-free DNase I (Promega). The integrity of RNA was analyzed by agarose gel electrophoresis. To check for DNA contamination, samples were analyzed with PCR using primers for benA. First-strand cDNAs were synthesized from $1 \mu \mathrm{g}$ of total RNA in a $20 \mu \mathrm{l}$ reaction volume using the Protoscript First-Strand cDNA Synthesis Kit (New England Biolabs, Ipswich, MA, USA).

For quantitative real-time PCR (Q-PCR) experiments, primer pairs, as shown in Table 2, were designed based on the published reference genome sequence of $P$. stutzeri A1501 using the Primer 4 server. Amplicons (100 to $200 \mathrm{bp}$ ) and reaction specificity were confirmed by agarose gel electrophoresis and product dissociation curves. Q-PCR reactions contained $1 \mu \mathrm{l}$ of cDNA, $10 \mu \mathrm{l}$ of $2 \times$ QuantiTect SYBR Green PCR Master Mix (Qiagen, Hilden, Germany), $0.5 \mu \mathrm{l}$ of each primer $(20 \mu \mathrm{M}$ stock), and $8 \mu \mathrm{l}$ of RNase-free water. Amplifications were conducted on an ABI PRISM 7000 Real Time PCR System (Applied Biosystems, Foster City, CA, USA) under the following conditions: $10 \mathrm{~min}$ at $95^{\circ} \mathrm{C}$, followed by 40 cycles of $15 \mathrm{~s}$ at $95^{\circ} \mathrm{C}, 31 \mathrm{~s}$ at $55^{\circ} \mathrm{C}$, and $31 \mathrm{~s}$ at $72^{\circ} \mathrm{C}$, followed by a melting-curve program $\left(55^{\circ} \mathrm{C}\right.$ to $99^{\circ}$ $\mathrm{C}$, with a 5-s hold at each temperature). Q-PCR data were analyzed using the ABI PRISM 7000 Sequence Detection System Software (Applied Biosystems). All cDNA samples were run in triplicate. The expression of $16 \mathrm{~S}$ rRNA was used as an internal control and the signal was used to normalize variations due to different reverse transcription efficiencies. The comparative CT (threshold cycle) method was used to determine the average fold induction of mRNA by comparing the CT of the target gene to that of the reference gene, as described previously [48]. The average fold change and standard deviation from three independent RNA samples are reported for each point tested.

High-performance liquid chromatography (HPLC) analysis To monitor metabolism, the $p c a D$ mutant and wild-type strains were grown in minimal medium supplemented with benzoate or a mixture of benzoate and 4-hydroxybenzoate. One-milliliter culture samples were centrifuged to pellet cells. Any cells remaining in the supernatant were removed by passage through a lowprotein-binding, $0.22 \mu \mathrm{m}$ pore size, syringe filter (MSI, Westborough, MA, USA). HPLC analysis was performed using an Agilent Technologies (Santa Clara, CA, USA) 1200 series chromatography system. A 20- $\mu$ l sample of the filtrate was analyzed on a C18 reverse-phase HPLC column (Agilent Technologies). Elution at a rate of 0.8 $\mathrm{ml} / \mathrm{min}$ was carried out with $30 \%$ acetonitrile and $0.1 \%$ phosphoric acid, and the eluant was detected at $254 \mathrm{~nm}$. Under these conditions, the retention times for benzoate, catechol, cis, cis-muconate, and 4-hydroxybenzoate standards were $6.071,2.388,3.358$, and $2.770 \mathrm{~min}$, respectively. Peak areas corresponding to standard and experimental samples were integrated using the manufacturer's software package (Agilent Technologies). 
Additional file 1: Time course of benzoate consumption and metabolite formation by the wild-type strain A1501. The elution profile of the compounds separated by HPLC is shown. Data in A-C are of samples taken at the indicated times. Conversion of benzoate (BEN) to catechol (CAT) and cis, cis-muconate (CCM) by A1501 is indicated by red vertical arrows.

Click here for file

[http://www.biomedcentral.com/content/supplementary/1471-2180-1036-S1.PDF ]

\section{Acknowledgements}

We would like to thank Dr. Russell Nicholson and Dr. Haiyang Wang for continuous support and critical reading of the manuscript. This work was supported by grants from the National Natural Science Foundation of China (No. 30925002, 30970093 and 30800022) and the National Basic Research (973) Program of China (No. 2010CB126504).

\section{Author details}

'College of Biological Sciences, China Agricultural University, Beijing 100094, China. ${ }^{2}$ Biotechnology Research Institute, Chinese Academy of Agricultural Sciences, Key Laboratory of Crop Biotechnology, Ministry of Agriculture, Beijing 100081, China. ${ }^{3}$ National Centre for Plant Gene Research, Beijing 100101, China.

\section{Authors' contributions}

$D L$ and $Y Y$ carried out the experimental work, interpreted the results, and drafted the manuscript. SP, MC, and WZ constructed the nonpolar mutants. $L L$ and WLin participated in RT-PCR and quantitative real-time PCR analysis. LG and WLiu carried out part of the HPLC analysis of intracellular metabolites. WLu and ML designed the research, analyzed data, and revised the manuscript. All authors have read and approved the final manuscript.

Received: 28 September 2009

Accepted: 8 February 2010 Published: 8 February 2010

\section{References}

1. Harwood CS, Parales RE: The beta-ketoadipate pathway and the biology of self-identity. Annu Rev Microbiol 1996, 50:553-590.

2. Jimenez Jl, Minambres B, Garcia JL, Diaz E: Genomic analysis of the aromatic catabolic pathways from Pseudomonas putida KT2440. Environ Microbiol 2002, 4(12):824-841.

3. MacLean AM, MacPherson G, Aneja P, Finan TM: Characterization of the beta-ketoadipate pathway in Sinorhizobium meliloti. Appl Environ Microbiol 2006, 72(8):5403-5413.

4. Barbe V, Vallenet D, Fonknechten N, Kreimeyer A, Oztas S, Labarre L, Cruveiller S, Robert C, Duprat S, Wincker P, Ornston LN, Weissenbach J, Marlière $P$, Cohen $G N$, Médigue $C$ : Unique features revealed by the genome sequence of Acinetobacter sp. ADP1, a versatile and naturally transformation competent bacterium. Nucleic Acids Res 2004, 32(19):5766-5779.

5. Butler JE, He Q, Nevin KP, He Z, Zhou J, Lovley DR: Genomic and microarray analysis of aromatics degradation in Geobacter metallireducens and comparison to a Geobacter isolate from a contaminated field site. BMC genomics 2007, 8:180.

6. Salinero KK, Keller K, Feil WS, Feil H, Trong S, Di Bartolo G, Lapidus A: Metabolic analysis of the soil microbe Dechloromonas aromatica str. RCB: indications of a surprisingly complex life-style and cryptic anaerobic pathways for aromatic degradation. BMC genomics 2009, 10:351.

7. Wu CH, Ornston MK, Ornston LN: Genetic control of enzyme induction in the $\beta$-ketoadipate pathway of Pseudomonas putida: two-point crosses with a regulatory mutant strain. J Bacteriol 1972, 109(2):796-802.

8. Houghton JE, Brown TM, Appel AJ, Hughes EJ, Ornston LN: Discontinuities in the evolution of Pseudomonas putida cat genes. J Bacteriol 1995, 177(2):401-412.

9. Cowles CE, Nichols NN, Harwood CS: BenR, a XylS homologue, regulates three different pathways of aromatic acid degradation in Pseudomonas putida. J Bacteriol 2000, 182(22):6339-6346.
10. Collier LS, Gaines GL, Neidle EL: Regulation of benzoate degradation in Acinetobacter sp. strain ADP1 by BenM, a LysR-type transcriptional activator. J Bacteriol 1998, 180(9):2493-2501.

11. Gerischer U: Specific and global regulation of genes associated with the degradation of aromatic compounds in bacteria. J Mol Microbiol Biotechnol 2002, 4(2):111-121

12. Tropel $D$, Meer van der JR: Bacterial transcriptional regulators for degradation pathways of aromatic compounds. Microbiol Mol Biol Rev 2004, 68(3):474-500.

13. Rothmel RK, Shinabarger DL, Parsek MR, Aldrich TL, Chakrabarty AM: Functional analysis of the Pseudomonas putida regulatory protein CatR: transcriptional studies and determination of the CatR DNA-binding site by hydroxyl-radical footprinting. J Bacterio/ 1991, 173(15):4717-4724.

14. Shingler $V$ : Integrated regulation in response to aromatic compounds: from signal sensing to attractive behaviour. Environ Microbiol 2003, 5(12):1226-1241.

15. Stulke J, Hillen W: Carbon catabolite repression in bacteria. Curr Opin Microbiol 1999, 2(2):195-201.

16. Moreno R, Rojo F: The target for the Pseudomonas putida Crc global regulator in the benzoate degradation pathway is the BenR transcriptional regulator. J Bacteriol 2008, 190(5):1539-1545.

17. Zimmermann T, Sorg T, Siehler SY, Gerischer U: Role of Acinetobacter baylyi $\mathrm{Crc}$ in catabolite repression of enzymes for aromatic compound catabolism. J Bacteriol 2009, 191(8):2834-2842.

18. Lalucat J, Bennasar A, Bosch R, Garcia-Valdes E, Palleroni NJ: Biology of Pseudomonas stutzeri. Microbiol Mol Biol Rev 2006, 70(2):510-547.

19. Jimenez Jl, Nogales J, Garcia JL, Diaz E: A genomic view of the catabolism of aromatic compounds in Pseudomonas. Handbook of Hydrocarbon and Lipid Microbiology Berlin Heidelberg: Springer-Verlag PressTimmis KN 2010, 1297-1325.

20. Yan $Y$, Yang J, Dou Y, Chen M, Ping S, Peng J, Lu W, Zhang W, Yao Z, Li H, Liu W, He S, Geng L, Zhang X, Yang F, Yu H, Zhan Y, Li D, Lin Z, Wang Y, Elmerich $C$, Lin M, Jin Q: Nitrogen fixation island and rhizosphere competence traits in the genome of root-associated Pseudomonas stutzeri A1501. Proc Natl Acad Sci USA 2008, 105(21):7564-7569.

21. Vodovar N, Vallenet D, Cruveiller S, Rouy Z, Barbe V, Acosta C, Cattolico L, Jubin C, Lajus A, Segurens B, Vacherie B, Wincker P, Weissenbach J, Lemaitre $B$, Médigue $C$, Boccard F: Complete genome sequence of the entomopathogenic and metabolically versatile soil bacterium Pseudomonas entomophila. Nat Biotechnol 2006, 24(6):673-679.

22. Qiu Y ZS, Mo X, You C, Wang D: Investigation of dinitrogen fixation bacteria isolated from rice rhizosphere. Chinese Sc bull (kexuetongbao) 1981, 26: 383-384.

23. Vermeiren $H$, Willems $A$, Schoofs $G$, de Mot R, Keijers $V$, Hai W, Vanderleyden J: The rice inoculant strain Alcaligenes faecalis A15 is a nitrogen-fixing Pseudomonas stutzeri. Syst Appl Microbiol 1999, 22(2):215-224

24. Rediers H, Bonnecarrere V, Rainey PB, Hamonts K, Vanderleyden J, De Mot R: Development and application of a dapB-based in vivo expression technology system to study colonization of rice by the endophytic nitrogen-fixing bacterium Pseudomonas stutzeri A15. Appl Environ Microbiol 2003, 69(11):6864-6874.

25. Rothmel RK, Aldrich TL, Houghton JE, Coco WM, Ornston LN, Chakrabarty AM: Nucleotide sequencing and characterization of Pseudomonas putida catR: a positive regulator of the catBC operon is a member of the LysR family. J Bacteriol 1990, 172(2):922-931.

26. Stover $\mathrm{CK}$, Pham $\mathrm{XQ}$, Erwin AL, Mizoguchi SD, Warrener P, Hickey MJ, Brinkman FS, Hufnagle WO, Kowalik DJ, Lagrou M, Garber RL, Goltry L, Tolentino E, Westbrock-Wadman S, Yuan Y, Brody LL, Coulter SN, Folger KR, Kas A, Larbig K, Lim R, Smith K, Spencer D, Wong GK, Wu Z, Paulsen IT, Reizer J, Saier MH, Hancock RE, Lory S, Olson MV: Complete genome sequence of Pseudomonas aeruginosa PA01, an opportunistic pathogen. Nature 2000, 406(6799):959-964.

27. Paulsen IT, Press CM, Ravel J, Kobayashi DY, Myers GS, Mavrodi DV, DeBoy RT, Seshadri R, Ren Q, Madupu R, Dodson RJ, Durkin AS, Brinkac LM, Daugherty SC, Sullivan SA, Rosovitz MJ, Gwinn ML, Zhou L, Schneider DJ, Cartinhour SW, Nelson WC, Weidman J, Watkins K, Tran K, Khouri H, Pierson EA, Pierson LS, Thomashow LS, Loper JE: Complete genome sequence of the plant commensal Pseudomonas fluorescens Pf-5. Nat Biotechnol 2005, 23(7):873-878. 
28. Romero-Steiner S, Parales RE, Harwood CS, Houghton JE: Characterization of the pcaR regulatory gene from Pseudomonas putida, which is required for the complete degradation of $\mathrm{p}$-hydroxybenzoate. J Bacteriol 1994, 176(18):5771-5779.

29. Guo Z, Houghton JE: PcaR-mediated activation andrepression of pca genes from Pseudomonas putida are propagated by its binding to both the -35 and the -10 promoter elements. Mol Microbiol 1999 32(2):253-263.

30. Harwood CS, Nichols NN, Kim MK, Ditty JL, Parales RE: Identification of the pcaRKF gene cluster from Pseudomonas putida: involvement in chemotaxis, biodegradation, and transport of 4-hydroxybenzoate. J Bacteriol 1994, 176(21):6479-6488.

31. Retallack DM, Thomas TC, Shao Y, Haney KL, Resnick SM, Lee VD, Squires $\mathrm{CH}$ : Identification of anthranilate and benzoate metabolic operons of Pseudomonas fluorescens and functional characterization of their promoter regions. Microb Cell Fact 2006, 5:1.

32. Parsek MR, Shinabarger DL, Rothmel RK, Chakrabarty AM: Roles of CatR and cis,cis-muconate in activation of the catBC operon, which is involved in benzoate degradation in Pseudomonas putida. J Bacteriol 1992, 174(23):7798-7806

33. Aldrich $\mathrm{TL}$, Chakrabarty AM: Transcriptional regulation, nucleotide sequence, and localization of the promoter of the catBC operon in Pseudomonas putida. J Bacteriol 1988, 170(3):1297-1304.

34. Fischer R, Bleichrodt FS, Gerischer UC: Aromatic degradative pathways in Acinetobacter baylyi underlie carbon catabolite repression. Microbiology 2008, 154(10):3095-3103.

35. Morales G, Linares JF, Beloso A, Albar JP, Martinez JL, Rojo F: The Pseudomonas putida Crc global regulator controls the expression of genes from several chromosomal catabolic pathways for aromatic compounds. J Bacteriol 2004, 186(5):1337-1344.

36. Park SH, Oh KH, Kim CK: Adaptive and cross-protective responses of Pseudomonas sp. DJ-12 to several aromatics and other stress shocks. Curr Microbiol 2001, 43(3):176-181.

37. Top EM, Springael D: The role of mobile genetic elements in bacterial adaptation to xenobiotic organic compounds. Curr Opin Biotechnol 2003 14(3):262-269.

38. Dobrindt U, Hochhut B, Hentschel U, Hacker J: Genomic islands in pathogenic and environmental microorganisms. Nat Rev Microbiol 2004, 2(5):414-424.

39. Ezezika OC, Collier-Hyams LS, Dale HA, Burk AC, Neidle EL: CatM regulation of the ben $A B C D E$ operon: functional divergence of two LysR-type paralogs in Acinetobacter baylyi ADP1. Appl Environ Microbiol 2006, 72(3):1749-1758

40. de Lorenzo V, Perez-Martin J: Regulatory noise in prokaryotic promoters: how bacteria learn to respond to novel environmental signals. Mol Microbiol 1996, 19(6):1177-1184.

41. Wong CM, Dilworth MJ, Glenn AR: Evidence for two uptake systems in Rhizobium leguminosarum for hydroxyaromatic compounds metabolized by the 3-oxoadipate pathway. Arch Microbiol 1991, 156(5):385-391.

42. Nichols NN, Harwood CS: Repression of 4-hydroxybenzoate transport and degradation by benzoate: a new layer of regulatory control in the Pseudomonas putida beta-ketoadipate pathway. J Bacteriol 1995, 177(24):7033-7040.

43. Xie Z, Dou Y, Ping S, Chen M, Wang G, Elmerich C, Lin M: Interaction between NifL and NifA in the nitrogen-fixing Pseudomonas stutzeri A1501. Microbiology 2006, 152(Pt 12):3535-3542.

44. Windgassen M, Urban A, Jaeger KE: Rapid gene inactivation in Pseudomonas aeruginosa. FEMS Microbiol Lett 2000, 193(2):201-205.

45. Schafer A, Tauch A, Jager W, Kalinowski J, Thierbach G, Puhler A: Small mobilizable multi-purpose cloning vectors derived from the Escherichia coli plasmids pK18 and pK19: selection of defined deletions in the chromosome of Corynebacterium glutamicum. Gene 1994, 145(1):69-73.

46. Figurski DH, Helinski DR: Replication of an origin-containing derivative of plasmid RK2 dependent on a plasmid function provided in trans. Proc Natl Acad Sci USA 1979, 76(4):1648-1652.

47. Staskawicz B, Dahlbeck D, Keen N, Napoli C: Molecular characterization of cloned avirulence genes from race 0 and race 1 of Pseudomonas syringae pv. glycinea. J Bacterio/ 1987, 169(12):5789-5794.

48. Pfaffl MW: A new mathematical model for relative quantification in realtime RT-PCR. Nucleic Acids Res 2001, 29(9):e45. doi:10.1186/1471-2180-10-36

Cite this article as: Li et al:: Genome-wide investigation and functional characterization of the $\beta$-ketoadipate pathway in the nitrogen-fixing and root-associated bacterium Pseudomonas stutzeri A1501. BMC Microbiology 2010 10:36.

\section{Submit your next manuscript to BioMed Central and take full advantage of:}

- Convenient online submission

- Thorough peer review

- No space constraints or color figure charges

- Immediate publication on acceptance

- Inclusion in PubMed, CAS, Scopus and Google Scholar

- Research which is freely available for redistribution

Submit your manuscript at www.biomedcentral.com/submit
C Biomed Central 